'Arts in psychotherapy journal' march 2010

\title{
PERSONAL DEVELOPMENT GROUPS IN POST GRADUATE DANCE MOVEMENT PSYCHOTHERAPY TRAINING: A STUDY EXAMINING THEIR CONTRIBUTION TO PRACTICE
}

\section{Helen Payne}

\begin{abstract}
There has been little research into the value of personal development (PD) groups in arts therapies/counselling/psychotherapy training, particularly in relation to trainees developing practice, despite a number of studies evaluating personal outcomes for trainees. Programmes assume trainees will benefit, however, how (or indeed if) the experience contributes to their actual practice has yet to be explored. This paper highlights findings from an analysis of the follow up data six months after the end of a weekly, 1.5 hour, DMT PD group for DMT trainees with reference to their reflections of the experience in relation to post-qualifying practice. The study was over three years, an intensive single cohort study which used qualitative methodology within a collaborative framework. Semi-structured interviews were undertaken $(\mathrm{N}=38)$ with trainees on a nationally validated, post graduate programme in dance movement therapy (DMT - now termed dance movement psychotherapy/DMP in the UK) in higher education. The aim is to stimulate debate and research on this aspect of training in body psychotherapy, arts therapies and counselling/psychotherapy, all of which appear to use groupwork for self awareness/personal development.
\end{abstract}

Key Words: Personal Development Groups; Dance Movement Therapy; Trainee Therapists; Practice; Higher Education. 


\section{INTRODUCTION}

This paper documents themes from the third phase of a qualitative, phenomenological, research study. It describes the analysis of findings from the seventh, final, follow-up interviews for each co-researcher (trainee) six months after ending their DMT group experience as trainees on a UK validated post graduate programme. In total 38 interviews were conducted during the two year group experience. These findings are hoped to be of assistance to those designing training programmes for arts therapies, counselling and body-oriented psychotherapies, in particular dance movement psycho/therapy. A critical literature review and methodology related to this study can be found in Payne (1999) and Payne (2004) respectively. Other major findings from this study concerned the 'question of safety' (Payne 2001); 'ferocious polar bears' as symbolic of destructive group forces (Payne 2002); 'becoming a practitioner-client' (Payne 2003) and 'the DMT approach, including loss and physical contact' (Payne 2006). The analysis of a global survey of PD groups in therapy training, including DMT, as a backdrop to the study can be found in Payne (2001a).

Studies in the arts therapies have yet to be undertaken in this highly significant area to training, but in the related field of counselling they are also fairly limited (Lieberman, 1981; Fairhurst \& Merry, 1999; Anderson \& Price 2001; Donati \& Watts 2000; Lennie 2000, 2005, 2007; Robson \& Robson 2008). In addition, to date the author has found no studies exploring the relationship between PD groups and trainees' placement or eventual practice. This was the question this research study engaged with from the perception of 
the UK trainees in Higher Education on a post graduate, two year programme to train as dance movement therapists.

Generally speaking PD groups are non-directive, closed and aim to 'offer opportunities for reflection on interactions and other important learning of counsellor [therapist] skills and processes' (Payne, 2004: 511). The literature suggests that developing self-awareness in the trainee arts therapist/counsellor practitioner is to be applauded and Johns (1996) claims trainees need to be open to a process of change. Grimmer and Tribe (2001) propose promoting this through mandatory personal therapy since it gives trainees insight into the role of the client. However, for some (e.g. Aveline 1990) the idea of coercing trainees to have therapy to pass a course goes against counselling ethics. Despite the lack of research most programmes in the arts therapies and counselling/psychotherapy do include an experiential PD group experience (Payne 1999, 2001b) as well as personal therapy, whether the training is applied to group work, individual therapy/counselling or both. This prevalent use of PD groups in training to give an experience of an 'as if' therapy group, and the importance most trainees place on this experience means the phenomenon is in need of systematic research. Conclusions from the limited literature and research in counselling are varied. Authors such as Irving and Williams (1999: 517) suggest the terms 'personal development' and 'personal growth' are poorly understood whilst others claim that the PD group is helpful in promoting counsellor skills, attitudes and personal development (Fairhurst \& Merry, 1999). Studies, though, conclude 'severe negative outcomes', indeed that there are some 'casualties' (Lieberman, 1981: 241) or that individuals may experience 'uneasiness' with this type of learning approach (Anderson \& Price, 2001). These contrasts are reflected in trainees' 
evaluations which show trust, empathy and genuineness were felt of a nature never before experienced, compared with those who disliked the PD group, commenting on its dysfunctional character (Lennie, 2000).

Mirroring this polarity are the analytic theories of groups, ranging from Foulkes' (1964) notion of the group as providing a source of growth, believing it to be an all-embracing, benign mother, to Bion's (1959) more gloomy focus on regressive, primitive fantasies and archaic patterns of relating to others. Nitsun (1996), on the other hand, argues that the hopeful conceptualisation of groups comes from our belief in the need for cohesion within a group. Nitsun claims destructive forces are essential if the group's creative potential is to be fulfilled, his theory uniting the polarity.

\section{METHODOLOGY}

A detailed outline of the methodology is well documented in Payne (2001b), but a brief overview is offered here. The main data collection tool was the recorded, individual, semi-structured interview which was conducted by a trained counsellor with interviewing skills. The recordings were transcribed by a transcriber and returned to co-researchers for their comments before being analyzed by the researcher. The interview schedule was designed by the researcher using material from the literature for the first and thenceforth the findings from the previous analysis. Trainees from year one were invited to participate in the study through informed consent prior to accepting their place on the programme. Full ethics approval was given for the study. All seven trainees volunteered, all female, between the ages of 30 and 45 years and white. Two were from continental Europe. After a year, one withdrew from the training and the research ${ }^{1}$. 
De-briefing meetings were held regularly with the research group to reflect on the process and consider ideas for changes in methods and so on. The approach was only collaborative to the extent that one co researcher analyzed her own data as well as the researcher.

The confidential nature of the PD group, alongside the constraints of researching live participants in a group environment results in difficulties methodologically. To overcome some of these it was arranged that the researcher, interviewer, transcriber, PD group facilitator and her supervisor were uninvolved in the training/assessment process. Only the researcher was involved in the study. Neither the interviewer nor the transcriber was aware of the identity of the participants. Apart from the researcher no one else was involved in the data ${ }^{2}$ analysis.

This study followed the experience of each co-researcher/trainee in the DMT PD group as studied through in-depth, semi structured interviews at each third of the way through the PD group journey (two years), and at six months follow up. It sought to encourage reflections on links made between their experiences in the PD group and their practice. This final, follow up interview presented here brought forward all previously analyzed themes as a guide to elicit further reflections concerning the trainee's previous placements and their current practice as qualified practitioners. The focus was on how, if at all, the DMT group influenced, or facilitated, their developing practice (as currently aware of) in terms of skills, capabilities, attitude, reflexivity and so on. Responses to questions analyzed for common and contrasting themes were built upon over time in a naturalistic, thematic analysis (Denzin and Lincoln 1994). 


\section{FINDINGS}

Five major distinct themes emerged from the inductive thematic analysis of the final interview: endings and loss; rivalry/envy/jealousy; own needs being met; anger and sexuality. There were seven sub-themes relating to practice, in addition.

\section{Endings and loss:}

Not surprisingly this was a prominent theme at this stage of the process. Loss of the regular contact with each other once the programme had ended was commented upon frequently by trainees. In addition, the loss of closeness and the solidarity of the group were both mentioned. There was sadness at the ending of their contact with an allwomen's group and this, together with DMT itself, were spoken of as rare and treasured experiences.

One co-researcher felt the loss of the reinforcement of the DMT group meant that this brought an end to her own experience of DMT, which she felt was necessary while practicing DMT in her work. Without DMT as personal therapy (since there were few practitioners in private practice) the DMT group may have been the only experience of how DMT could work, and this enriching experience was now lost to the newly qualified practitioners.

Ending their DMT group gave trainees more experience for when closures were required in their practice. For example, as one co-researcher put it: 'it [the DMT group ending] helped me in making my own groups aware of endings even though they cannot express anything verbally' (these were non-verbal clients). By being aware of her own processes 
in ending the DMT group this participant went on to say she had ensured that her clients were aware of the reasons for their group ending and gave them space to say goodbye. If, for some reason, the ending/goodbyes had not been undertaken she said she felt 'at a loss...the consequences of not saying goodbye seem more for the therapist's needs than the client's, to relieve her guilt feelings'.

There was also awareness of endings highlighting loss. 'Comprehension of reasons for an ending gave meaning to loss, but did not necessarily alleviate the feelings', commented another co-researcher. It was important that' loss made rationale sense' claimed another: 'To just disappear would give them a greater sense of loss. If no reason is given [for the ending] clients can loose trust. There needs to be a certain amount of trust left intact in endings, and in building trust and security in beginnings when setting up new groups this is important to remember'.

Every ending can, potentially, be the foundation for a more secure beginning according to psychodynamic thinking. In every beginning the end is acknowledged in the way that beginning happens. Endings stimulate feelings of loss not only of the group, its members and facilitator but also of past or current life losses. One co-researcher recognised her feelings of loss would be powerfully re-stimulated in the beginning and letting go stages of a new DMT practice group. She felt it too problematic to set up a group to run at this phase of her life (she had lost both parents and her partner during the lifetime of the DMT group).

'I decided not to run a DMT group, post qualifying, to give me time to get over the losses. I couldn't give it the safety, contain anything, or differentiate my stuff from theirs. I am always tired, in a giving-up mood, a sort of passivity, the lethargy. I've recognized there is always interference as a constant interruption but I am not capable now of looking into these at different levels. In my gut there's still too much pain down there'. 
She tells us she recognizes the interface between the personal and the professional.

Another group means another loss to her, just too painful to experience as yet. In deciding to give herself more time to heal, she respects her client's needs for her to be there for them as a primary objective, and she simply cannot do that for the time being. Although she understands there will always be interferences from her personal life in her work she cannot process her losses on the many levels required if she facilitated a clinical DMT group. She admits the pain, located in her gut, is too great. Perhaps there is a belief in operation here that in order to work as a therapist she requires the pre-requisite of a lack of pain at the psycho-physiological level. Her comment poses the question as to whether the therapist has a responsibility to consider if, as a result of these interferences, she is fit to work and the possible yardstick for this self-assessment. This co-researcher wanted to work with groups focusing on loss and bereavement issues after she felt more healed herself. She thought going through her own losses in the context of the DMT group had prepared her well for the grief etc in running such groups in the future though.

Another co-researcher spoke of the facilitator sharing her feelings of loss in the final session of the DMT group which had helped her to learn about endings in her own practice:

'It was very moving to see her openly share her grief of loosing the DMT group - us- and that was important to witness. I realize it was brave for the therapist to talk like that to the group. When I'm ending groups I tend to block a bit, sort of cover up and put on more of a professional front, as a way of not really getting in touch with my own pain about the group ending. Seeing that happen in the DMT group and the effect it had on me I realize the value of being honest with your feelings, and sharing your pain openly to the group when ending, rather than showing a false front. It showed me it was really OK to be there really present at the ending, and not to be one jump ahead or behind. It's a way of giving the group permission to release feelings, a role model. If that stuff doesn't come out in the group where is it going to go? It's going to be taken and spattered all over the place. The 
real power and healing in the ending is bringing the pain of that ending into the ending and dealing with it in the present space'.

Awareness of the importance of endings was reflected in other attitudes towards endings in their practice. For example, one comment revolved around clients knowing the beginning and end dates, and ensuring they were aware of the end date, even though they were non-verbal children on the whole. She said: 'The last session was different from all the others, so they were aware of the ending by this. Even though they couldn't express anything about it, they could non-verbally'. At one school this ending did not take place and she was left feeling 'at a loss'. She visited each child to say goodbye individually, but felt unfinished and 'in passing'. She thought they would be thinking of additional things with others around them. She felt angry with the school for denying them the opportunity, and guilty that she had been unable to make it happen for them.

Poor endings can have consequences for the therapist as well as clients. Another coresearcher was absent for the final DMT group sessions due to bereavement in her close family. Her reflections illustrate a profound awareness that she had a desire to hang onto the DMT group members as a reaction to this loss of the ending phase. Her comments seem to allude to an ambiguity of endings in relation to practice: 'Endings aren't always clear cut so you have to tolerate the loss and lack of resolution sometimes'.

An interesting finding was that of the continuation of the research project beyond the ending of the DMT group affected the ending experience of both the programme and the DMT group in particular. 'its presence took away from the ending a little', commented one co-researcher,... 'as we all knew we would be meeting again it was cushioned - the 
ending - because we all knew we would salvage something - there would still be a connection. I do think about what it would have been like if it had been ending, curtains!' Perhaps they felt cheated of a real ending due to the research because all but the facilitator would be meeting up again for a de-briefing of the research and final individual interviews, albeit with a different purpose, context and with the primary researcher - a stranger to the DMT group. On the other hand, on-going contact with each other, the researcher and the reflection process was very much appreciated: 'we reflected on the study of the inquiry into the DMT group!'

One co-researcher pointed out that although the life of her practice DMT group might end these participants still had on-going relationships with one another as they lived in the same place, unlike the participants in the DMT group. However, it was linked to the ongoing contact the co-researchers had with one another because of the research project following the DMT group. She went on to say that in this situation she felt, as a therapist, that she held far more of the feelings of ending (grief in particular) in her practice group than in the DMT group. She wondered if the DMT group facilitator was openly sad in that last session because she knew the trainees would continue to meet together for the research fieldwork, post-DMT group ending.

Another co-researcher noted her difficulties with being on the 'inside/outside' of the DMT group and how, in her practice, it was hard not to feel, as the therapist, that she was on the 'outside'. She was sad at not having taken the opportunity to process these 'insider/outsider' feelings more in the DMT group, as they were now arising in her practice. Processing them might have enabled a greater sense of belonging to both the DMT group during training, and to her practice group, to understand and empathise with 
inclusion - exclusion feelings as they arose for her clients. In her current practice she mentioned feelings of exclusion towards her, as a therapist, together with feelings of rejection and abandonment by the client group. How the therapist deals with these powerful themes is crucial to the therapeutic process, and her relationship with the organisation as a context for that work. For example, if the therapist feels on the outside, as a sessional worker (one who is paid by the session/hour rather than on the permanent staff) to a hospital or school, any action by the organisation towards her or her group may be interpreted as a threat to her or rejecting of her/the group, for instance. If this is not processed by the therapist in supervision then it may get acted out (by her or the group) in a reaction towards the organisation or in her facilitation of the group - by becoming angry with them or needy of them, for example.

\section{Rivalry, envy and jealousy:}

A co-researcher said it was 'too frightening to work with rivalry and jealousy in the DMT group'. It did get addressed in certain exercises though, she admitted, such as in intensive weeks and skills workshops. Here she discusses the matter of jealousy from fellow professionals in her practice setting when she was a sessional therapist, going in weekly.

'There is no model for how to cope with jealousy as a therapist. I learned about myself in the DMT group and about the role of the therapist - when she stepped in - and when she did not. As a therapist I would try to encourage the group to deal with rivalry and jealousy. To be honest it's never such a disaster as you think it's going to be. Usually people grow from situations such as those. People end up in therapy through a lack of honesty in their lives so in leading a group I would go for it. As a sessional therapist the OTs, and others who are with the clients every day, are envious because I only go in once a week, for two hours. There is novelty about my group, and my presence because I do a different sort of activity. It can be felt by someone who is a bit jaded in their work that the visiting therapist has all the star quality, which you have not'.

The same co-researcher continues to reflect on the issue of envy in her practice: 
'Envious people can be destructive and not helpful in a group. I learnt in the DMT group the power of reflection, so all that has been set in motion and I do use it. I acquired a range of situations, not just rivalry, which enabled me to reflect at the end of a practice group session. Sorting out a way to deal with it and thinking about it in supervision. If I saw aggression it might remind me of what happened in the DMT group and that might set off memories to recognise it might be about rivalry say, rather than a desire to be Mickey Mouse, (laugh) - it might be a clue.'

Rivalry in their DMT practice groups revolved around competition for the facilitator's attention (or to hold her hand in one case!), or rivalry between group members, often disguised as anger. This experience of expressing rivalry was specifically mirrored in the experiential DMT group for most trainees. This quotation from one co-researcher illustrates how she used the training DMT group model, and her experience of it, to run her groups differently:

'I have been trying to show my groups I cannot share myself around, everyone get a bit...I tend to run my groups in a different way. A lot about being together at the beginning of the session and then perhaps splitting off because of the nature of the children (with severe learning disabilities).Then, after one-to-one work with staff, to all return together at the end, acknowledge the group again, as one group, at the end of the session'.

Another co-researcher pointed out she now realised how important it was to have such feelings as rivalry and jealousy 'out' and 'worked with', particularly if group members were also 'meeting each other outside the therapy sessions'. She used imagery as a vehicle to help members explore unwanted, unclaimed parts of themselves, such as competitive tendencies. She had learned this technique from the PD DMT group, as she describes in the metaphor below:

'Like in the DMT group when the facilitator suggested we select and become an animal. I became a slithery lizard, warts, red eyes and with a flicking, salivary, tongue. It was safer to project my feelings into this foul creature than confront the group with my envy'.

In the DMT group feelings of jealousy were difficult to work with. Instead they appeared to have been split off. One co-researcher spoke of how another member voiced to her 
'that there was a feeling of jealousy towards me in the group - a relief to me to hear this but quite shocking. It was less dangerous if talked about, but rarely was this the case in the group'.

This experience helped her to understand the importance of addressing jealous and rivalrous feelings in her clinical groups. For example, in her hospital DMT group clients held onto old, jealous feelings in the group, perhaps due to a lack of safety. Consequently, they appeared to prefer to act them out on the ward rather than address them in the group.

\section{Own needs being met:}

Trainees' own needs for self exploration in an 'as if client' role, identified in the preDMT group questionnaire analysis were met in a primary way (Payne 2004), but the influences of this exploration on practice was also evident as a tracing into the final interviews. For example:

'The DMT group enabled me to explore myself as a person and within the group. It has certainly enabled me to carry on. Discovering a kind of inner strength, having gone through a lot of loss, I needed to know I had a kind of reserve. If I got through all the pain that the bottom line was I was OK, strong enough'.

The implication here is the need to develop an inner strength and that stages have to be worked through to appreciate that she was fundamentally ' $\mathrm{OK}$ '. She was aware in her practice individuals may never reach such a place, particularly when most of her groups were short-term unlike the DMT group, which she saw as a limitation on growth. She enlarged on the concept of 'ego strength' (Freud 1960) as being needed in order to 'individuate' (Jung 1989), to break away from the personality of the group, which she acknowledged, may not be possible for most of her clients.

Overall comments evaluated the DMT group as providing a stronger sense of self - a classic aim of psychotherapy. For example: 'Expanding on all levels, becoming more of 
who I am'. However, some participants revealed a reluctance to explore specific private aspects of themselves. Reasons included not yet being ready to be open and preferring an individual setting or self help groups for such disclosures. One co-researcher made a connection with her practice DMT group on this issue:

'I'm always aware that anyone I'm working with, especially women and young girls, in special needs settings who are pre or non-verbal are quite vulnerable. They may well have been exposed to levels of abuse whether it be sexual or physical. I always hold that in mind and I don't think I was aware of this before, I mean I used to read about it, but now it is more specific'.

In relation to practice, lower grades for assignments mattered less to trainees than 'doing it [practicing DMT] their own way'. This connects with another aspect whereby the DMT group model during training was explored in students' own practice, but found to be inappropriate for many of their clients (Payne 2006). Therefore, they concluded, they were required to formulate their own model of practice of DMT in relation to those client populations with which they were now working. In other words, their own development of both 'being' and 'doing' was seen as crucial to practice.

In addition, co-researchers were able to point out how an awareness of their own needs and motivations linked to their practice. For example, they were conscious of the fact that in selecting a particular client population or issue they were unconsciously responding to their own needs. One participant was able to reflexively consider her motivation for being in training and working with a particular population:

'It [the DMT group] has made me realize this incredible link that makes it very important to constantly watch out and see why you are doing a group. Or what makes you pick a topic. Why does one become a therapist? And why with this particular population?'

As she continued it became clear she believed in the task of the therapist as 'helper' and in the importance of the therapist's experience of her own personality and history being 
intimately connected with their work on particular issues and/or their choice of particular client populations.

\section{Anger:}

Anger was a constant theme in the DMT group in the co-researchers' view both during it and at follow up. Much anger appeared to have been projected onto the facilitator rather than onto each other, they thought. The experiences of 'release' in contrast to the 'inhibition of anger' enabled co-researchers to become aware of how to predict experiences of anger in their own groups. For example, practicing in a residential setting, one commented insightfully on how this very dependent, and vulnerable, client group may find the expression/experience of anger difficult since it might jeopardize their relationships with one another outside the DMT group. This mirrored comments concerning the difficulties the DMT members had in expressing anger to each other as they were peers for the remainder of the day in teaching groups, and relied on each other for support. Although all new to one another beforehand, being a small cohort, on a newly emerging programme, may have resulted in them feeling vulnerable and apart from the rest of the arts therapies department, particularly since DMT had very little political power in the organization, and in the UK at that time. Consequently, the inhibition of anger towards each other may also have been due to their closeness as a result of their vulnerability.

Other participants' practice groups were 'open-groups' with clients coming and going on a weekly basis making a multiplicity of relationships. Although their PD group was not an 'open-group' or a 'therapy' group per se, co-researchers thought they learned about the 'delicacy and boundaries of relationships' by being part of a constant, 'closed' DMT 
group since there were absences and even members leaving. One co-researcher described how a particular technique used by the facilitator in the DMT group which she experienced as confronting at the time actually enabled her own practice at a later date:

'The autistic lad spent the first two sessions hiding. I acknowledged his hiding. He was building a box out of cushions and hiding inside, looking through a gap. I poked my head through the gap and left him to work his own way out. He may have felt gently confronted. He managed to get though. I learnt that gentle confrontation techniques which give the client the space to think about it, be angry perhaps but then to work through that anger with them'.

Another commented: 'I learned anger can come about if there is resistance in the environment.' And another said: 'I was so frightened of anger until it was shared in the DMT group situation'.

\section{Sexuality:}

'In schools I get passing comments in the staff room like; well if you could stop him masturbating it would be fine... So it is about taking the movement, masturbating rhythms and finding a different way for him to be able to release rather than physically. I did not have a problem with the children masturbating in my groups'.

This was one student's comment concerning the theme of sexuality. She does not appear phased by the subject matter communicated to her. Instead she reflects on how she might use the rhythms inherent in the child's masturbation, which appears to be of concern to staff at the school, to help the child to express himself and release tension in a more appropriate manner.

However, nearly all trainees found the issue of sexuality difficult to work with in the DMT group. Comments indicate some were working with the issue of their own sexuality consistently throughout the DMT group, but in a private way rather than overtly, or in terms of how it affected the group. It was admitted that the all-female gender group could have blocked the development of the group in certain directions. To have had a man in 
the group might have introduced other issues around sexuality/gender. They felt the issue was 'conveniently skipped over'. Some felt it was surprising not to have been consciously raised as two members were lesbian in sexual orientation. The belief here seems to be that if the group were heterosexual, sexuality would not have been an issue. The lack of overt processing of it left at least one co-researcher at a loss when dealing with it in her practice groups. However, it appears from some trainees that they believed that if the group was all-women there would be no issue around gender/sexuality. One acknowledges she needs to process aspects of her own sexuality for it to be addressed in groups. The fact that most of her groups were female apparently results in it not arising at all, and even with a man in the group it remained hidden (albeit not from her it seems).

'It is something I would have to work through myself if I wanted to run a group. Most of my groups are all-female. One group had a male in it and it did come up there but under the surface, never addressed'.

Another co-researcher connected her inability to have children with homosexuality:

'It links with homosexuality because she is young and (silence...) I won't have any children [due to her age].She won't either as she is a lesbian and...um...so it would have been something I would have liked to work through in the DMT group'.

This comment implies some anger or envy towards the younger member. Perhaps some of the expressed anger in the DMT group was a result of such underlying feelings being repressed, rather than being expressed and processed. This raises some anxiety as to whether the issue of gender, sexuality and sexual orientation could ever be raised in participant's clinical practice groups. 


\section{SUB-THEMES IN LEARNING TO PRACTICE}

Several other sub-themes arose when the co researchers responded to the same question of how the DMT group, as a PD group, facilitated their learning about practice, if it did at all. These themes are documented next:

Continuity: The regularity of the time and place for the group helped co-researchers to create similar conditions and boundaries for their own clients. An environment where consistency was seen as crucial was appreciated.

Movement and the body: The nature of DMT means movement is particularly stressed as the medium for expression. As such there was an expectation of movement in the group. The body was given permission to be present in the same way as words. Learning how to encourage movement expression without necessarily moving as the therapist was seen to be very valuable for practice. The modeling of this by the facilitator was helpful to trainees. In the DMT group trainees had been willing and ready to move. Hence the facilitator had no real obstacle in supporting this, their non-verbal expression. However, at times it was noticed by co-researchers that she appeared a little anxious, for example one member commented: 'I was aware she was anxious to try and get us going and I was sort of thinking, well why did she do that, why couldn't she have left us?' Here there is a reflection that perhaps it might be appropriate for the facilitator to allow participants at their level to activate movement themselves, or not, rather than 'getting them going'. Personal therapy for the trainees was often verbal so without the DMT group experience co-researchers thought they would not have necessarily made connections with the way the body/movement aspect might be supported or not by the therapist. 
The self limiting therapist/client: Co-researchers, on reflection, thought they could have done much more with some issues/feelings in the DMT group. Now, in their practice, the clients who were unable to 'break through' and move into/out of feelings were more easily recognized, they felt, as a result of their own experiences in the group. They could empathise with these clients in their practice groups more easily now, they said. However, they thought there was less known to them about how to practically help such clients. This stickiness with current clients appeared to be directly related to how stuck they felt at times in the DMT group. At this point they claimed they felt no encouragement or guidance from either the group, or the facilitator, on how to process their feelings in a deeper way, that is beyond their self limits i.e. those limitations they imposed upon themselves about how deeply to explore.

Criteria for going 'freelance': On a more pragmatic note, co-researchers were able to feel confident enough, following their training, to become self employed in their work. One discovered she was ' $O K$ ' and gained confidence and a belief in herself and what she was doing as a result of the DMT group experience. She was able to decide to take the plunge and 'go it alone' as a practitioner. She felt able to sell DMT to other professionals in hospital and school settings due to the recognition that it 'seemed to work for her'. This recognition seemed to reinforce to her that it would therefore be ' $\mathrm{OK}$ ' for others to experience too. Armed, in addition, with an understanding, at a bodily, cognitive and affective level, that the 'as if' therapy group gave opportunities to process issues: 'the process part of a therapy group provides experience of issues concerned with the totality of what the person or group experience is at the time'. This participant went out into the wider world to persuade others to employ her to run DMT groups on a sessional basis. 
The experience of being a client: This was still seen as a valuable aspect of the DMT group on follow up (Payne 2004). The group provided them with a strong sense that DMT was the right path for them, professionally, but also that DMT had an intrinsic value, which had been experienced personally, a foundation on which to build their professional practice.

'I believe in DMT and its value because I have personally been through it. It would feel like I still lacked something if I said 'I can set up a DMT group' and that 'I know about DMT because I've read all the books'. But I'd really not know what it might be like to be a client in a DMT group. You have to have that if going to practice DMT. I can guarantee it is going to be hard work for clients. I have experienced the pros and cons. Not that my clients will have the same experience as me. It can be very valuable though, knowing it from inside of a person, rather than from [a theoretician's name], so it must be so'

Another co-researcher summed up this internalisation of being a DMT client:

'The best was that it activated a journey, which I will be on for the rest of my life wanting to enable other people, to facilitate some process for them. Not a week goes by without me being transported back to the DMT group. I feel I carry the group with me'.

Short term versus long term groups: One co-researcher considered these structures in

her practice. Most participants groups were short term and closed. However, she felt these groups never got to the stage where they were strong enough for the individuation of participants, as she had experienced in the long term DMT PD group:

'The DMT group gave us the space to explore ourselves as a group and actually form a group, and be aware we were working as a group to become more individual in that group. I wonder how long they (her client group) need as a group to be strong enough to do this, given the nature of these groups? Due to limitations of funding we cannot always have open-ended groups though'.

This comment indicates the model provided in the PD group during training (closed and long term) was unsuitable to be adopted wholesale to the populations being worked with following training and connects to trainees need to develop their own models for practice (see above 'own needs being met' and findings in Payne, 2006). 


\section{Non-participation:}

'In one DMT session I felt in the group, not bolshie [a UK term for obstinate] exactly, but more 'this is where I want to go, from here to B to C to B, and you can all lump it! This is who I am' - I think the facilitator reflected this back to me which made me notice it more. In my practice I'm more aware when people are definite, more or less, and when I am more or less confident about a session, even though it hasn't been a good one but I still feel good about it. To look out for an atmosphere of people getting on with their own thing. Not necessarily doing the same thing together, but getting on with doing their own, different things. They are all working but it's hard to see the whole group - I'm struggling with that in the groups I run'.

Co-researchers felt they rarely worked as a whole group i.e. doing the same thing together as a group. One participant felt this lack of a feeling of wholeness and sameness was why she found it hard to see the whole group in her work now. Perhaps participants believe that if group members are too involved with 'doing their own thing' there is an element of non-participation in, or self-exclusion from, the group, resulting in a lack of connection between members. It was also proposed that non-participation was the voice of 'wanting to join in but in a different, oppositional way to others in the group'.

'It is not necessarily where a member wants to be, moving in the whole group, but rather where they don't want to be, and so in practice there needs to be much flexibility to be helpful to these members'.

Another commented that she believed adults who had not 'danced' would not know what to do in movement therapy so she would give movements in a structured warm up.

Perhaps being dancers or from a dance/movement background these trainees may not appreciate that adults can move naturally and authentically without having to have structured 'warm ups'. In other words, it might have been a limitation of this DMT group to have only catered for trainees with dance training since assumptions were made about the general population: 
'It was a real learning for me to go against the group and the facilitator... If I ran a group for high functioning adults I'd want to use the free model presented in our DMT group. I would make it clear they don't have to move with others and that I'm not going to tell them what to do or how to move. But if they had never danced before what do they do?... To give a directive warm up might be helpful at first and then come together at the end to facilitate talking'.

From their comments it is evident co-researchers thought there was a process of learning to be undertaken in order to engage in non-participation. Not moving as a whole group, not joining in structures suggested by the facilitator, and not moving at the same time or in the same way as other group members were all seen as examples of non-participation in the group. Some clients, they thought, might require structures in order to participate at the outset of a group session, particularly if they had little formal movement vocabulary. They also believed clients may need encouragement to talk.

\section{The research study:}

Finally, it is worth noting that the research process and the interviews themselves were commented upon favorably by co-researchers. These were seen to have been fruitful experiences, 'a harvesting of the experiencing of the learning in the DMT group' as one co-researcher put it. Surely all research should give something back and/or be transformational for all participants.

\section{DISCUSSION}

To return to the major themes described above feelings concerned with 'endings and loss' are to be expected at this last stage as the research group also finally comes to a close. Coresearchers do appear to be extremely aware of the impact of endings, absence and so on through the reflections on their own experiences of these phenomena in the PD DMT group. This consciousness may enable their 'lived experience' of these issues to be 
imported into the way they facilitate their client groups in the future. Certainly in the six months from the end of the PD DMT group there is some evidence they are already addressing these important aspects of group process with mindfulness.

Rivalry, envy and jealousy will often be present in groups since it will raise early infantile feelings. Therapists, whatever their orientation, need to take account of when these powerful feelings are present, and help the group to integrate them, otherwise members will experience a lack of holding and containment possibly leading to the group destruction. The repetitive theme of 'anger' (released versus inhibited) probably indirectly expresses fear, restriction and resistance as well as these competitive feelings above. Endings are bound to raise feelings of anger for a group, whether they annihilate the group or are resolved depends on its cohesiveness and acceptance of its own safety (Payne 2002). The study's ending at follow up probably added to these feelings, however they appeared to be conscious and contained by the group itself. Destructive processes or the 'anti group' (Nitsun 1996) threaten the functioning of the group. Underlying anticipated fear, anxiety, frustration of narcissistic needs, aggression and distrust contribute to the threat, often confirmed by the actual experience of the group. Facilitators and participants, by recognizing and understanding the anti group may feel empowered to contain and limit destructive urges of the group, harness the aggression and help transformation akin to Winnicott's (1960) creative destruction. In DMT this can take the form of facilitating the symbolic expression, modulation and transformation of frustration, anger and rage in the self reflective psychological imagination (Chodorow 2009). Consequentially, it is crucial to give DMT trainees the experience of symbolizing their own feelings as part of a training programme, experiential methods such as the PD 
group can provide the opportunities for these imperative experiences, and the resulting understanding to be learned for practice.

Sexuality, based as it is in the body, can be a charged subject in groups, especially when there is physical contact and attention to sensory processes, however it is rarely made explicit. Training in the non-sexual use of touch is essential in a body oriented psychotherapy, such as DMT. Participants appear to believe they have not sufficiently integrated 'sexuality', and connected to this 'touch', into their overall practice. Some basic rules on the use of touch might have enabled sexuality to have been more explicitly addressed in the group, such as 'touch should not be aggressive, sexual, against the client's wishes or to gratify the therapist's needs' (Tune 2005:76). In some orientations touch has been linked to the expression of adult sexuality, and if used would break the notion of therapist abstinence, interfering with transference. But this notion was founded in Victorian Europe's repressive sexual attitudes. Touch is being re-evaluated in attachment theory as concerned with pre-oedipal levels and the need for holding - being safely mothered (Bar-Levi 1998; Rothschild 2000; Orbach 2004). DMT is highly supportive of work with these pre-verbal, regressive moments and, as such, is holistic, employing the understanding and tools from psychodynamic verbal psychotherapy to its own specialist training.

The paucity of males is common in most therapy/counselling programmes, and will be experienced by any group as a missed opportunity to process tensions between the genders. Although the ideal of even numbers of male and female, as in analytic groupwork training, would be unreasonable to expect, sometimes even only one or two men can help the group to address important issues such as the loss itself. It is 
recommended recruitment to programmes encourage men specifically, if at all possible, especially since clients will probably be 50 per cent male.

Shame and anxiety often surround the exploration of sexuality in a group (Nitsun 1996), since revealing sexual wishes/concerns means revealing deeper recesses. Primitive, destructive, regressive elements of the early, unconscious, primal scene may be acted out in the group, perhaps disguised symbolically. It may be appropriate for these to remain symbolic, although the practitioner needs to recognize what it is in order to assist the group/client to process the feelings/fantasies. Group facilitators and theory modules on DMT training programmes might consider how this important issue can be given an explicit consideration, particularly in relation to erotic transference, embodied countertransference (Soth 2005, 2006) and ethical practice. The theme of 'own needs being met' in the DMT group connects to the earlier major theme of 'safety' (Payne 2001) which arose repeatedly during the process of the DMT group. The co-researchers' later reflection of 'feeling safe to be themselves' in the group, six months after its ending, may provide their future clients (through this 'knowing') with more possibilities to have their needs met. In a similar counselling study (Robson and Robson 2008) aiming to develop a greater understanding of the creation, maintenance and importance of safety within PD groups, noted 'creating such safety seems to be vital in ensuring effective therapeutic environments' (ibid: 381).Therefore, as one co-researcher said 'accepting oneself through feeling safe enough to be oneself' a core value appeared to have become internalized, enabling co-researchers to facilitate levels of safety for their clients to 'be themselves' in their own post-qualifying DMT groups. And perhaps assisting trainees to be 'more themselves' and entrepreneurial as is necessary when 
creating a DMT practice (see 'going freelance' sub-theme above), remembering we are all pioneers in DMT, although this was much more so at the time these first UK practitioners qualified.

Gibb (1964) states that a person learns to grow through an increasing acceptance of himself and others, requiring a non-judgemental attitude of mind in the facilitator and, it must be said, a feeling of safety. Perhaps in developing more acceptance of themselves they have in place more of a non judgemental attitude, crucial when working with the client populations who are so marginalised and judged in our Western society. Bowlby (1988) illustrated the importance of a secure base for the developing infant, surely it is a similar need for the developing therapist, to feel a sense of security in themselves when beginning their unknown, unsafe, journey into their practice as newly emerging therapists. Hurley and Rosenburg (1990) state in their analysis of studies reported by Rogers (1957) and Barrett-Lennard (1962) that authentic and congruent leader -behaviours were associated with greater learning by group members. It could be speculated, given similar group experiences to those studies in Rogers and BarrettLennard, the more learning is drawn from a PD group, the more authentic and congruent the trainee therapists/counsellors will become in their leader-behaviours and attitudes. Connor (1994) researching PD groups in counselling advocates taking the ambiguity out of the PD group by giving students an overview of group theory/dynamics/guidelines at the start, then allowing them to set personal objectives, reviewed regularly. As has been demonstrated in this study, it may be a transferable finding to say that students having the group in mind, as they experience it, appears to provide them with reflexivity on how the group is understood, and meets their objectives, especially when related to current and 
future practice.

\section{SUMMARY}

There been no rigorous exploration of the value/experience of the PD group despite its requirement on all training programmes accredited by professional associations in DMT (such as ADMP UK), counselling and the other arts therapies. The PD group remains a mystery, unquantifiable in aim and outcome but with hugely potent effects which surely need to be harnessed and harvested for the benefit of the trainee and their future clinical practice. This study was an attempt to understand the experience of a DMT PD group and identify factors which are thought to be helpful in informing and promoting eventual, effective clinical practice.

The major themes from the analysis of the final, follow up interviews of a three-year research study were presented. The study explored the value for practice of a closed, 'as if' therapy group in the form of a two-year PD DMT group experience. All students/coresearchers were in two different placements during the study and, after qualifying, facilitated their own DMT groups (and individuals) in various settings in health and education.

It is hoped both trainees and trainers of arts therapies as well as counselling/psychotherapy programmes will find this in-depth analysis of trainee perceptions of interest when engaged in any teaching/assessment in which there is an element of PD groupwork. It is decided to include elements of a training programme because there is sufficient evidence that each provides the desired outcomes such as competencies, attitudes of mind, knowledge, understanding and skill. Otherwise, to include them on a whim or simply because they have always been there, wastes the 
trainee's time and teaching/assessment is less efficient resulting in poorly trained practitioners and the consequential effects on clients.

It appears the PD group experience was particularly helpful when explicitly and consciously reflected upon, and linked, to learning in practice, as it was in this study's methodology. In this way trainees can utilize the group experience to enhance the development of their practice, both during and following, the training process. It is therefore anticipated programmes aiming to train therapists/counsellors will find ways to assist students to make links in their learning between the PD group experience, theoretical understanding and clinical placement practice.

\section{Acknowledgements}

Many thanks to all the co-researchers who participated in this research study, to the academic supervisor, Professor Helen Simons, University of London; the DMT group facilitator, the clinical supervisor, interviewer and the transcriber. Thanks also to the University of Hertfordshire who funded part of the dissemination of findings.

\section{References}

Anderson, R.D. \& Price, G.E. (2001) Experiential groups in counsellor education: student attitudes and instructor participation. Counselling Education and Supervision, 41, 2, 111 119.

Aveline, M. (1990) Training and supervision of individual therapists. In: W. Dryden (Ed.) Individual Therapy: a Handbook. Milton Keynes: Open University Press. 
Bar-Levav, R. (1998) A rationale for physical touching in psychotherapy. In: EWL.

Smith; PR. Clance and S. Imes (eds) Touch in psychotherapy. London: The Guildford press

Barrett-Lennard, G. (1962) Dimensions of therapist response as causal factors in therapeutic change. Psychological Monographs, 76 (Whole no: 562).

Bion, W.R. (1959). Attacks on linking. International Journal of Psycho-Analysis, vol.40, reprinted in: W. Bion (1967) Second Thoughts: Selected Papers on Psycho-Analysis. London: Heinemann.

Bowlby, J. (1988) A secure base. London: Routledge.

Chodorow, J. (2009) Dance therapy, motion and emotion. In: Chaiklin, S and Wengrower, H. (eds) The art and science of dance movement therapy. London: Routledge.

Connor, M. (1994) Training the counsellor: An integrative model. London: Routledge. Donati, M \& Watts, M. (2000). Personal development groups in counselling psychology training: the case for further research. Counselling Psychology Review, 15, 1, 12-21. Denzin, N. and Lincoln, Y. (Eds.) (1994) Handbook of qualitative research. Thousand Oaks, CA: Sage.

Fairhurst, I. \& Merry, T. (1999). Groupwork in client centred counsellor training. In: Lago, C. \& Macmillan, M. (Eds) Experiences in Relatedness: Groupwork and the Person Centred Approach . Ross-on-Wye: PCCS Books.

Foulkes, S.H. (1964). A Memorandum on Group Therapy, Oxford: British Military Memorandum. ADM. 
Freud, S. (1960) Strachy, J (ed). The Ego and the Id (The Standard Edition of the Complete Psychological Works of Sigmund Freud). New York: WW Norton and Co.

Gibb, J. (1964) Climate for trust formation. In: L. Bradford, J. Gibb, \& K. Benne (Eds.), T-group theory and laboratory method (pp. 279-301). New York: Wiley.

Grimmer, A. \& Tribe, R. (2001) Counselling psychologists' perceptions of the impact of mandatory personal therapy on professional development - an exploratory study. Counselling Psychology Quarterly, 14, 4, 287-301.

Hurley, J \& Rosenburg, D. (1990). Group members' gain in acceptance of self and others associated with leader's behaviour. Genetic, Social and General Psychology Monographs, 116, 4, 413-434.

Irving, J.A. \& Williams, D.I. (1999). Personal growth and personal development: concepts clarified. British Journal of Guidance \& Counselling, 27, 4, 517-526.

Johns, H. (1996) Personal Development in Counsellor Training. London: Cassell. Lennie, C. (2000). The role of personal development groups in counsellor training. Unpublished MA dissertation, University of Manchester. Jung, C. G. (1989). Memories, Dreams, Reflections (Rev. ed., C. Winston \& R. Winston, Trans.) (A. Jaffe, Ed.). New York: Random House, Inc.

Lennie, C. (2005). The role of personal development groups in counsellor training: a process of developing self awareness for the trainee counsellor, researcher and person. Unpublished PhD thesis, University of Manchester. Lennie, C. (2007) The role of personal development groups in counsellor training: understanding factors contributing to self-awareness in the personal development group. British Journal of Guidance \& Counselling, 35, 1, 115-129. 
Lieberman, M.A. (1981) Analysing change mechanisms in groups. In: B. Bates and A. Goodman (1986). The effectiveness of encounter groups. British Journal of Guidance and Counselling. 14, 3, 240-250

Nitsun, M. (1996) The Anti-group: Destructive Forces and their Creative Potential. London: Routledge.

Orbach, S. (2004) There is no such thing as a body. In: K. White (ed) Touch, attachment and the body. London: Karnac Books.

Robson, M. and Robson, J. (2008) Explorations of participants' experiences of a Personal Development Group held as part of a counselling psychology training group: Is it safe in here? Counselling Psychology Quarterly, 21, 4, 371- 382.

Payne, H. (1999) Personal Development Groups in the Training of Counsellors and Therapists: A Review of the Research. European Journal of Psychotherapy, Counselling and Health, 2, 1, 55-68.

Payne, H. (2001a) A Comparison between Personal Development Groups in arts and psycho therapy training: An international survey. On-line International Journal for Arts Therapies, University of Derby, 1, 1. http://www2.derby.ac.uk/v-art/vol-1-200102international-arts-therapies-journal/36-refereed-articles-

Payne, H. (2001b) Students' experiences of a Dance Movement Therapy Group: The Question of Safety. The European Journal of Psychotherapy, Counselling and Health, 4, 2, 167-292.

Payne, H. (2002) Ferocious Polar Bears: Student Perceptions of a Dance Movement Therapy Group. German Dance Therapy Journal, 1, 22, 60-77 (in German), Payne, H. (2004) Becoming a Client, Becoming a Practitioner: Student Narratives from a 
Dance Movement Therapy Group. British Journal of Guidance and Counselling, 32, 4, $512-532$.

Payne, H. (2006) The lived experience of students in a dance movement therapy group: loss, physical contact and the DMT approach.

London and New York: Routledge.

Rogers, C. (1957) The necessary and sufficient conditions of therapeutic personality change. Journal of Counseling Psychology, 21, 95-103.

Rothschild, B (2000) The body remembers: the psychophysiology of trauma and trauma treatment. London: WW. Norton.

Soth, M (2005a) Embodied countertransference. In: N. Totton (ed) New dimension in body psychotherapy Milton Keynes: Open University Press.

Soth, M. (2006) What therapeutic hope for a subjective mind in an objectified body? International Journal of Body, Movement and Dance in Psychotherapy, 1, 1, $43-$ 56.

Tune, D. (2005) Dilemmas concerning the ethical use of touch in psychotherapy. In: N.

Totton (ed) New dimension in body psychotherapy Milton Keynes: Open University Press.

Winnicott, DW. (1960) The maturational process and the facilitating environment. London: Pelican. 


\footnotetext{
${ }^{1}$ It should be noted this study took place in the first, nationally validated programme in DMT at post graduate level in the UK. The curriculum was based in UK/European theory and practice and an integrative psychotherapeutic theoretical perspective. In addition, all students were requested to undertake weekly, individual psychotherapy in an orientation of their choosing.

${ }^{2}$ This final interview relied on evidence from only four co-researchers, one absent due to bereavement and another poor recording. However, each interview was more than one and a half hours in duration, providing for rich, in-depth data.
} 